\title{
Tekrar Doldurmalı Sürtünme Karıştırma Nokta Kaynaklı 6061-T6 Alüminyum Alaşımıı Bağlantıların Mikroyapı ve Mekanik Özelliklerinin İncelenmesi
}

\author{
Mustafa AY ${ }^{1 *}$, Kürşat DEMIR ${ }^{2}$, Furkan SARSILMAZ ${ }^{1}$ \\ ${ }^{1}$ Mekatronik Mühendisliği Bölümü, Teknoloji Fakültesi, Fırat Üniversitesi, Elazı̆̆, Türkiye \\ 2 Jandarma Genel Komutanlığ \\ ${ }^{1}$ Mekatronik Mühendisliği Bölümü, Teknoloji Fakültesi, Fırat Üniversitesi, Elazı̆̆, Türkiye \\ ${ }^{* 1}$ mustafaay@firat.edu.tr, ${ }^{2}$ kursatdemir62@gmail.com, ${ }^{1}$ f.sarsilmaz@firat.edu.tr
}

(Geliş/Received: 28/02/2021;

Kabul/Accepted: 03/06/2021)

\begin{abstract}
Öz: Bu çalışmada, 6061 T6 alüminyum alaşımlarının katı hal kaynak yöntemlerinden biri olan tekrar doldurmalı sürtünme karıştırma nokta kaynağı (TSKNK) ile birleştirilebilmesi araştırılmıştır. AA6061 kaynak bağlantıları, takım dönme hızı (2000$2500 \mathrm{dev} / \mathrm{dk})$, kaynak süresi(1-1.5sn), dalma derinliği (1.7-2.0-2.5mm) olmak üzere üç farklı kaynak parametreleri kullanılarak gerçekleştirilmiştir. Yapılan mikroyapısal inceleme sonucunda kaynak bölgesinde karıştırma bölgesi (KB), 1sıdan etkilenen bölge (IEB), termo-mekanik etkili bölge (TMEB) ve temel malzeme (TM)olmak üzere 4 farklı bölge tespit edilmiştir. Varyans analizi (ANOVA) sonucunda dalma derinliği parametresinin \% 96,76 katkı oranı ile çekme dayanımı üzerinde en etkili parametre olduğu tespit edilmiştir.
\end{abstract}

Anahtar kelimeler: Tekrar doldurmalı sürtünme karıştırma nokta kaynağı, AA6061, Varyans analizi (ANOVA).

\section{Investigation of Microstructure and Mechanical Properties of Refill Friction Stir Spot Welded 6061-T6 Aluminum Alloy Joints}

\begin{abstract}
In this study, the ability of joining 6061 T6 aluminum alloys with refill friction stir spot welding (RFSSW) which is one of the solid state welding methods is investigated. AA6061 welded joints are produced by using three different welding parameters which are tool rotational speed (2000-2500 rpm), welding time (1-1,5 s), plunge depth (1,7-2,0-2,5 mm). Four different zone which are stir zone (SZ), heat affected zone (HAZ), thermo-mechanically affected zone (TMAZ) and base material was determined as a result of microstructural investigation. As a result of the analysis of variance (ANOVA), it has been determined that the depth of immersion parameter is the most effective parameter on the tensile strength with $96.76 \%$ contribution rate.
\end{abstract}

Key words: Refill friction stir spot welding, AA6061, Analysis of variance (ANOVA).

\section{Giriș}

Alüminyum alaşımları, yüksek mukavemet, düşük ağırlık oranı, yüksek korozyon direnci, kolay şekillendirebilme, çok iyi termal ve elektrik iletkenliği gibi üstün özellikleri sebebiyle havacılık, otomotiv gibi sektörlerde yoğun olarak kullanılmaktadır [1]. Son yıllarda otomotiv üreticileri, uzay çerçeve yapılarındaki ekstrüde alüminyum borular ve uçak gövde iç ve diş paneller için alüminyum levhalar gibi çok çeşitli alüminyum ürünlerden iyi bir şekilde yararlanmaktadırlar [2]. Ayrıca bu sektörlerin imalat kısmında alaşımlı çeliklerin yerine alüminyum alaşımlı malzemelerin kullanılması, sistemin ağırlığını azaltılması nedeniyle uçak, otomotiv gibi araçlarda enerji (yakıt) tasarrufu sağlama hususunda önemli fayda sağlamaktadır [3].

Geçmişten günümüze uçak ana gövdesini birleştirmek için cıvata, vida, perçin gibi bağlantı elemanları kullanılagelmiştir. Fakat bu tarz birleştirme metotları kullanılan ek malzemelerden dolayı ana gövdenin ağırlığını artırmaktadır [4]. Alüminyum alaşımlarının kullanımında avantajlarının olması ile beraber montajında, kaynak yapılabilmesinde karşılaşılan bir takım sorunlar, yapılan bilimsel araştırmalarla aşılmaya çalışılmaktadır. Alüminyum alaşımlarının ergitme kaynak yöntemleri ile birleştirilmesi işleminde doğan problemler, araştırmacıları yeni birleştirme yöntemleri geliştirmeye yönlendirmiştir. Belirtilen bu olumsuz sebeplerden dolayı, bu malzemelerin birleştirilmesinde katı hal kaynak yöntemleri büyük avantajlar sağlamaktadır.

Özellikle son 10 yılda katı hal nokta kaynağı olan Sürtünme Karıştırma Nokta Kaynağı (SKNK) alüminyum alaşımları gibi kaynak edilmesi zor malzemelerin birleştirilmesinde direnç nokta kaynağı ve perçinleme

\footnotetext{
* Sorumlu yazar: mustafaay@firat.edu.tr. Yazarların ORCID Numaras1: ${ }^{1} 0000-0002-9056-9975,{ }^{2}$ 0000-0003-3408-3505, ${ }^{1} 0000-0001$ $5351-8645$
} 
metodunun yerini almaktadır. SKNK yönteminde, çalışan malzemeler arasında oluşan sürtünme 1sısı birleşecek malzemeleri yumuşatır ve dönerek hareket eden mil, malzeme akışına sebep olmaktadır. Dövme basıncı ve plastize edilmiş malzeme katı bir bağlantı bölgesi oluşturmaktadır [5]. SKNK' nin maliyeti direnç nokta kaynağından \% 25 daha düşüktür. Ayrıca, SKNK süreci değişen malzeme cinsine ve malzemelerin yüzey koşullarına duyarlı değildir. Ek olarak, SKNK yöntemi su, basınçlı hava veya elektrik dönüştürme gibi ek ekipmanlara ihtiyaç duymaz [6-9]. Fakat SKNK yönteminin sağlamış olduğu bu yenilik ve avantajların yanı sıra bazı dezavantajlarının da olduğu tespit edilmiştir. Bunlardan en önemlisi kaynak sürecinden sonra oluşan anahtar deliğidir. Anahtar deliği kaynak bölgesinde artık gerilme yoğunluğuna, çentik etkisine ve bağlantı alanının azalmasına neden olmaktadır. $\mathrm{Bu}$ gibi olumsuzluklar, bağlantıların mekanik özelliklerini olumsuz etkileyen kusurlardır. Ayrıca, dıș ortamda kullanılan plakalarda korozif etkileri giderebilmek için uygulanan gövde boyasının anahtar deliğine tam olarak nüfuz edemeyeceği için potansiyel korozyon başlama noktası oluşur. Bu ve benzeri dezavantajları ortadan kaldırmak için SKNK yerine daha yüksek kaynak mukavemeti sağlayan Tekrar Doldurmalı Sürtünme Karıştırma Nokta Kaynağı (TSKNK) geliștirilmiștir. Helmholtz-Zentrum Geesthacht tarafindan geliștirilen bu yöntemde, bir baskı bileziği, bir kovan ve bir pimden oluşan Şekil 1'de görüldüğü gibi üç parçalı bir takım kullanılmıştır. Bu takım sayesinde kovan daldırma, pim ise yeniden doldurma işlemini gerçekleştirerek kaynak sonrası anahtarsız bir bağlantının oluşması sağlanmıştır [11].

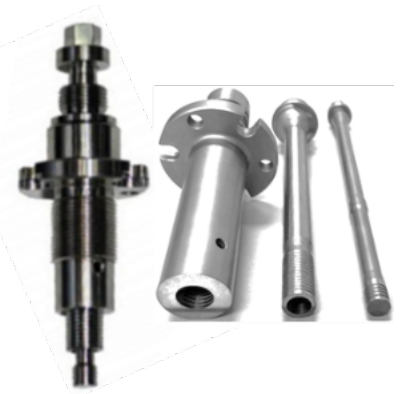

Şekil 1. Tekrar doldurmalı sürtünme karıştırma nokta kaynağı takımı

Alüminyum alaşımlarının TSKNK bağlantılarının mikroyapısı ve mekanik özellikleri araştırılmaya devam etmektedir. Li vd. [12], 2024-T4 alüminyum alaşımlı levhaları birleştirme işleminde TSKNK yöntemini kullanmış ve orijinal bindirme ara yüzü ve termal-mekanik olarak etkilenen bölge ara yüzünün, bağlantının zayıf bölgesi olduğunu rapor etmiştir. Xu vd. [13] 5053-O alüminyum alaşımlı levhaların birleştirilmesinde hem pim hem de kovan dalma derinliğinin kaynak kusurlarının ortadan kaldırılmasında önemli rol oynadığını belirtmişler. Tier vd. [14] tarafindan 5042-O alüminyum alaşımlarının TSKNK yöntemi ile birleştirilmesinden sonra işlem parametrelerine bağlı çekme dayanımı, mikroyapısal özellikleri incelenmiştir. Uygulanan parametre değerleri ve takım özellikleriyle yapılan deneyler dikkate alındığında, en etkili parametrenin dalma derinliği ve sonrasında dönme hızı olduğu tespit edilmiştir. Nasiri vd. [15] 2099-T83 alüminyum alaşımlarının birleştirilmesinde TSKNK takımının hasar mekanizması üzerine çalışma yapmışlar. Çalışma sonucunda, 4 ve 6 nolu kaynak işleminden sonra takıma ait hareket eden parçalarda ve takımda ciddi hasar tespit etmişlerdir. Kubit vd. [16] 7075-T6 alüminyum alaşımlı levhalar arasına iki farklı sızdırmazlık maddesi (fenol-formaldehit reçine bazlı yapıştırıcı ve epoksi reçine bazlı bant) yerleştirilerek elde edilen plakaları TSKNK yöntemi ile birleştirerek kaynak bölgesinin korozyon direncini ve kaynak mukavemetini araştırmışlardır. İncelemeler neticesinde, polimer ara tabakayla desteklenmiş levhaların kaynağında, yük taşıma kapasitesinin yaklaşık \% 9'dan \% 28'e düşürdüğü. Bununla birlikte, polimer ara tabakasının kaynak bölgesi korozyon direncini önemli ölçüde artırdığını bildirmişlerdir. Yapılan çalışmalarda, TSKNK yönteminde güçlü bir birleştirmenin elde edilebilmesi için uygun kaynak parametrelerinin belirlenmesinin gerekliliği vurgulanmıştır. Bu çalışmada, havacılık ve otomotiv sanayinde yaygın olarak kullanılan 6061-T6 alüminyum alaşımı TSKNK yöntemi ile birleştirilmiştir. Kaynak işleminde kullanılan parametrelerin (kaynak süresi, dalma derinliği, takım dönme hızı) kaynak bölgesi mikroyapısı ve mekanik özellikleri üzerindeki etkileri araştırılmış, ayrıca kaynak parametrelerinin etkinlik dereceleri varyans analizi (ANOVA) kullanılarak saptanmıştır. 


\section{Deneysel Çalışma}

\subsection{TSKNK sürecinin temel prensibi}

TSKNK yönteminin işlem aşamaları Şekil 2'de gösterilmiştir [17]. Uygulama üç parçadan oluşan (Bask1 bileziği, kovan ve pim) takım tertibatı kullanılarak gerçekleştirilmektedir. Takımın üç bileşeni, eş eksenli olarak monte edilmiş ve birbirinden bağımsız olarak döndürülebilirken, birbirinden bağımsız yukarı ve aşağı hareket ettirilebilmelerini sağlayan bir mekanizma tarafından kontrol edilmektedir. İşlem temelde iki aşamadan oluşur. İlk olarak, birleştirilecek parçalar üst üste konumlandırılarak alt ve üst baskı plakalar ile sıkıştırılıp sabitlenir. Sonra dönen takım ile iş parçası arasında sürtünme 1sısı oluşturularak malzemenin viskoz hale gelmesi sağlanıp basıncın etkisiyle birleştirilme işlemi gerçekleştirilir [18].

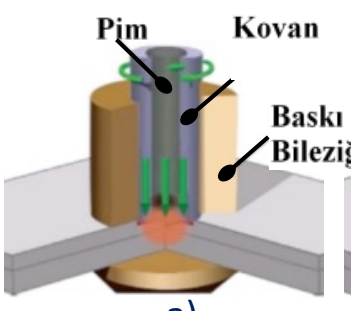

a)

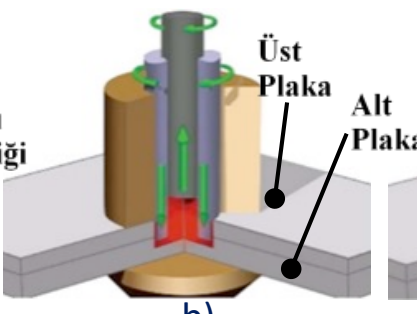

b)

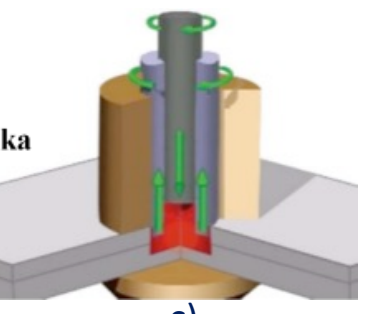

c)

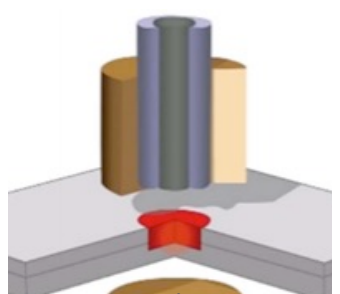

d)

Şekil 2. TSKNK işleminin şematik gösterimi [17].

Şekil 2'de gösterildiği gibi, TSKNK süreci dört farklı aşamayla açıklanabilir:

a) Baskı bileziği, plaka çiftlerini sıkıştırarak sabitler, hem kovan hem de pim dönmeye başlar ve dalma işleminde viskoz malzeme oluşturabilmek ve malzemeyi plastize edebilmek için belli bir süre parça üzerinde sürtünme 1S1s1 oluşturur

b) Kovan ve pim sırasıyla aşağı-yukarı yönde hareket eder, bu nedenle kovan tarafından karıştırılan plastize olmuş malzeme pimin yukarı doğru hareketi ile oluşan silindirik boşlukta sıkıştırılır.

c) Önceden belirlenmiş dalma derinliğine ulaştıktan sonra, Kovan ve pim ters yönde hareket etmeye başlar ve silindirik boşluktaki plastize edilmiş malzeme kovan tarafından geriye doğru sıkıştırılır.

d) Takım iş parçasından uzaklaştırılır.

\subsection{Numune hazırlama ve deneysel tasarım}

Tablo 1' de çalışmada kullanılan AA6061-T6 plakaların kimyasal içerikleri verilmiştir. Plakalar, kaynak işlemi için 2x28x100mm boyutlarında kesilip, yüzeyleri asetonla temizlenerek kaynak deneylerine hazırlanmışlardır.

Tablo 1. 6061 T6 alüminyum alaşımı kimyasal bileşenleri

\begin{tabular}{|l|l|l|l|l|l|l|l|l|l|}
\hline $\mathrm{Fe}$ & $\mathrm{Si}$ & $\mathrm{Cr}$ & $\mathrm{Mn}$ & $\mathrm{Mg}$ & $\mathrm{Zn}$ & $\mathrm{Cu}$ & $\mathrm{Ti}$ & Diğer & Al \\
\hline 0,5 & $0,6-1,0$ & 0,1 & $0,2-0,8$ & $0,8-1,2$ & 0,25 & $0,6-1,1$ & 0,1 & 0,15 & Kalan \\
\hline
\end{tabular}

Bütün numunelerin birleştirme işlemleri, bu işlem için özel olarak tasarlanmıș RPS100 TSKNK makinasında gerçekleştirilmiştir. Ana makinenin çalışma değerleri sırasıyla; dönme hızı 3000 dev/dk, güç çıkışı 2,2 kW, dalma hızı 3,6 mm/sn, maksimum basma kuvveti $11 \mathrm{kN}$ 'dur. Kaynak işlemlerinde kullanılan takımın baskı bileziği 15 $\mathrm{mm}$, kovan $9 \mathrm{~mm}$ ve pim $5 \mathrm{~mm}$ çapındadır. Plakaların bindirme mesafesi ise $28 \mathrm{~mm}$ olarak belirlenmiştir. Kaynak sonrası Şekil 3'de gösterilen 4x28x172mm boyutlarında kaynaklı numuneler elde edilmiştir. 


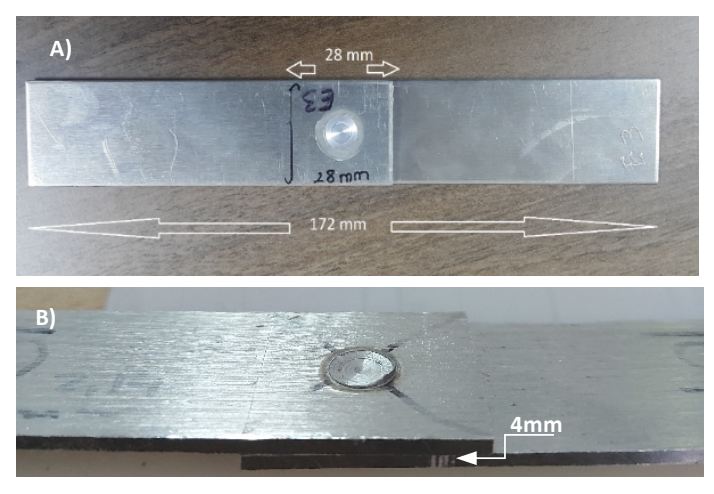

Şekil 3. Kaynak işlemi sonucunda elde edilen numunenin üst (a)ve kesit (b) görünüşü.

Tam Faktörlü Tasarım, bir ürünün, sürecin, tasarımın veya sistemin performansının zaman ve maliyet açısından optimize edilmesini sağlayan güçlü bir istatistiksel yöntemdir. Varyans analizi (ANOVA) kullanımıyla birleştirildiğinde, Tam Faktörlü Tasarım, kaynak işlemi parametrelerinin mekanik özellikler üzerindeki göreceli önemini belirlemek ve optimum işlem çıktılarını tespit edilebilmektedir. Tam Faktörlü Tasarım, daha az sayıda faktör ve seviyenin seçildiği durumlarda en uygundur. TSKNK'da, ana işlem parametrelerinin ve bunların değer aralıklarının doğru şekilde seçilmesiyle elde edilebilir.

Kaynağın mukavemetinin değerlendirilmesi için üç faktörlü (takım dönme hızı, dalma derinliği ve süre) ve 3;3;2 seviyeli bir deney düzeni seçilmiştir. Tablo 2 de bu çalışmada kullanılan işlem parametreleri ve bu parametrelerin seviyeleri verilmiştir.

Tablo 2. Deney parametreleri ve değerleri

\begin{tabular}{|c|c|c|c|}
\hline \multirow{2}{*}{ Numuneler } & \multirow{2}{*}{$\begin{array}{l}\text { Kaynak Süres } \\
\text { "t" (saniye) }\end{array}$} & \multicolumn{2}{|c|}{ Dalma Derinliği|Takım Dönme Hızı } \\
\hline & & “h“" (mm) & “v” (dev/dk) \\
\hline A & 1,0 & 1,7 & 2000 \\
\hline $\mathrm{B}$ & 1,0 & 1,7 & 2500 \\
\hline $\mathrm{C}$ & 1,0 & 2,0 & 2000 \\
\hline $\mathrm{D}$ & 1,0 & 2,0 & 2500 \\
\hline $\mathrm{E}$ & 1,0 & 2,5 & 2000 \\
\hline $\mathrm{F}$ & 1,0 & 2,5 & 2500 \\
\hline $\mathrm{G}$ & 1,5 & 1,7 & 2000 \\
\hline $\mathrm{H}$ & 1,5 & 1,7 & 2500 \\
\hline I & 1,5 & 2,0 & 2000 \\
\hline $\mathrm{J}$ & 1,5 & 2,0 & 2500 \\
\hline K & 1,5 & 2,5 & 2000 \\
\hline $\mathrm{L}$ & 1,5 & 2,5 & 2500 \\
\hline
\end{tabular}




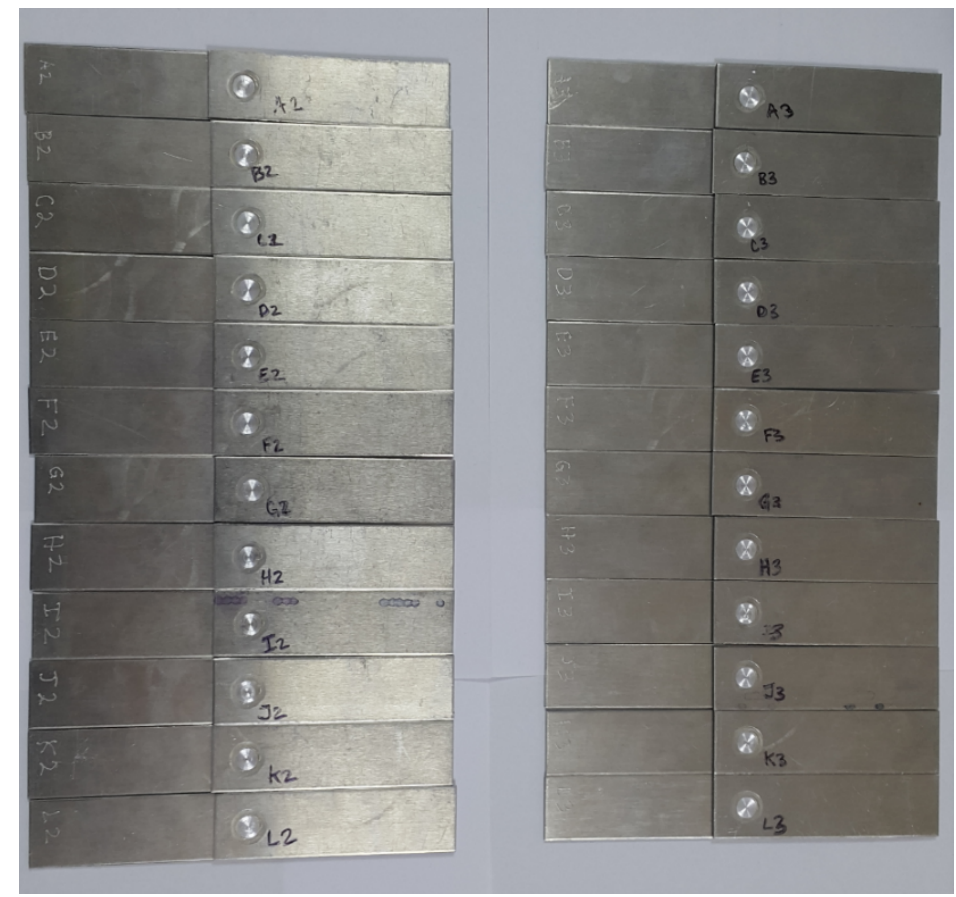

Şekil 4. Kaynak işleminden sonra bütün numunelerin görüntüsü

Farklı parametrelerde 12 adet olmak üzere hem çekme testi için hem de mikroyapı incelemeleri için Şekil 4'de verildiği gibi toplam 24 adet numune birleştirilmiş̧ir. Kaynak işleminden sonra, metalografik incelemeler için kaynak bölgesi merkezine dik kesit alınarak yüzey zımpara ve çuha yardımıyla parlatılmışır. Ayrıca $85 \mathrm{ml}$ $\mathrm{H}_{2} \mathrm{O}, 2 \mathrm{ml} \mathrm{HF}, 10 \mathrm{ml} \mathrm{H}_{2} \mathrm{SO}_{4}$ asit çözeltisi kullanılarak kesit yüzeyler dağlanmıştır. Kaynaklı numunelerin mekanik özelliklerini belirlemek amacıyla Şekil 5'de görülen test cihazında 12 adet numune çekilmiştir. Numunelerin mikro sertlik ölçümleri Tronic DHV-1000 Micro Vickers sertlik ölçüm cihazında 300 gr yük altında 15 saniye bekletilerek yapılmıştır. Ölçümlerde kaynak merkezinden ana malzemeye doğru $2 \mathrm{~mm}$ aralıklarda ölçüm alınmıştır.

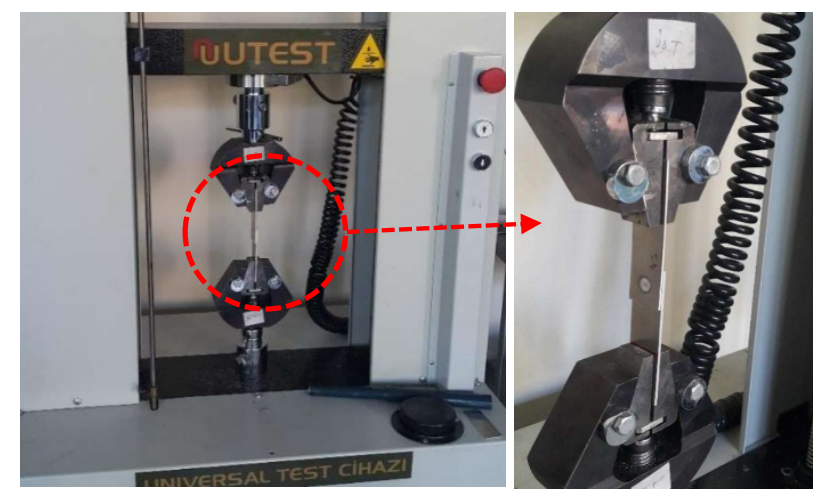

Şekil 5. Numunelere uygulanan çekme testi

\section{Bulgular}

\subsection{Mikroyapı analizi}

Şekil 6a ve b' de L numunesine ait kaynak kesitinin makro ve mikro görüntüsü verilmiştir. Şekil 6a'da TSKNK sonrası ara kesitte 4 farklı bölgenin varlığı görülmüştür. Bunlar sırasıyla kaynağın merkezindeki Karıştırma 
Bölgesi (KB), onun bitișiğinde 1sı ve basıncın etkisiyle tanelerin yönlendiği Termo-Mekanik Olarak Etkilenen Bölge (TMEB), ve bu bölgenin yanında dinamik taşınıma dahil olmayan fakat ısı tesiri altında bulunan Isıdan Etkilenen Bölge (IEB) ve son olarak Temel Malzeme (TM) şeklinde literatüre uyumlu olarak belirlenmiştir $[16,19,20]$. Kaynak işlemi sonrası kaynak merkezinde herhangi bir boşluk ve bağlantısız bölgenin varlığı görülmezken, anahtar deliğinin başarılı bir şekilde yeniden doldurulduğu görülmektedir.
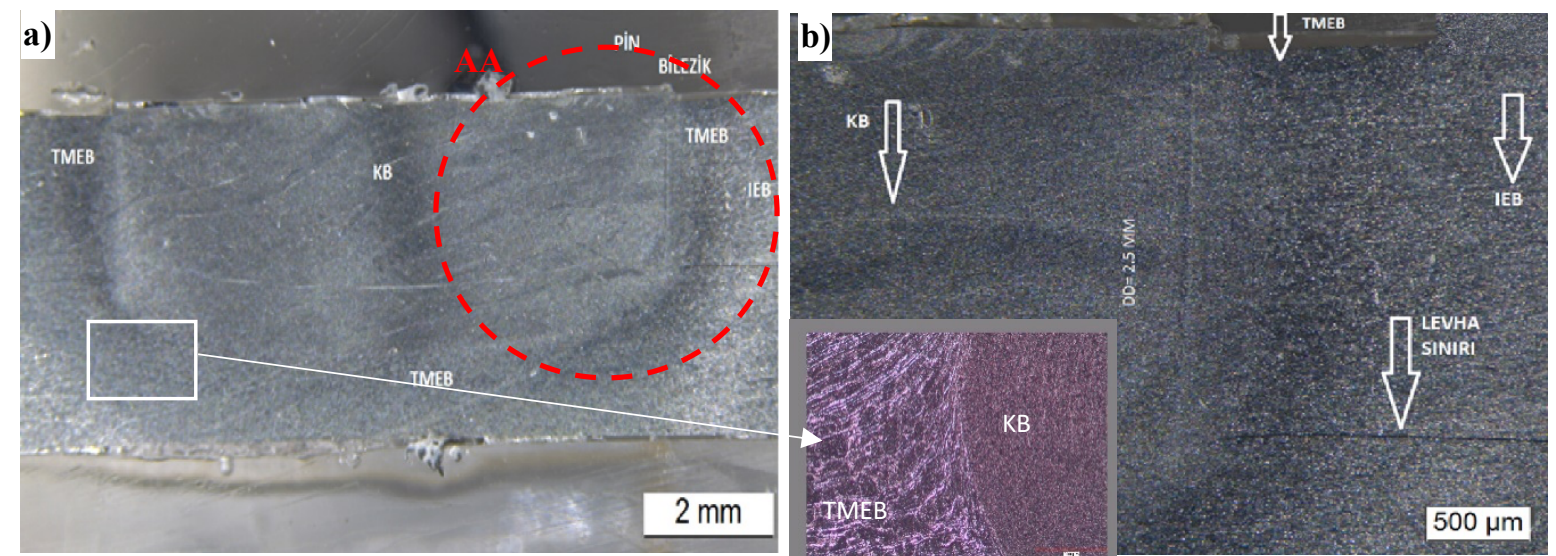

Şekil 6. $\mathrm{t}=1.5 \mathrm{sn}, \mathrm{h}=2.5 \mathrm{~mm}, \mathrm{v}=2500 \mathrm{dev} / \mathrm{dk}$ parametreleri ile yapılan L numunesine ait kaynaklı birleştirmenin: (a) kaynak bölgesinin kesiti, (b) AA kesitin büyültülmüş görüntüsü.

Kovanın dönme hızı, dalma basıncı ve bekleme sürelerine bağlı olarak oluşan KB bölgesinde, aşırı dövülmüş tanelerden oluşan bir yapının varlığı görülmüştür. Bu durum kaynak merkezinde takımın ana malzemeyi dövmesi sonucu tanelerin incelmesine yol açmıştır. Kaynak merkezinde aşırı plastik deformasyona maruz kalan içyapının homojen dağılımlı yeniden kristalleşen ince taneli bölgeden oluştuğu mikroyapı fotoğraflarından net olarak görülmektedir. Ayrıca TMEB olarak adlandırılan bölgede, KB bölgesinde aşırı dövülen ve viskoz hale gelmiş malzemenin kovan ve karıștırıcı pimin dönme yönüne bağlı olarak malzeme taşınımıyla taneleri yönlendirip daha uzun ve yönlenmiş tanelerin oluşmasına neden olduğu ve termomekanik etkilenen bölgeyi oluşturduğu ilgili literatür 1şığında Mishra vd. [21] düşünülmektedir. Ayrıca hem 1sı hem de dövme etkisinde kalan kaynak ara bölgesine kıyasla herhangi bir plastik deformasyona uğramamış fakat takımın malzeme üzerinde hareketinin oluşturduğu ısıdan etkilenen, iri tanecik yapısına sahip olan bölge IEB olarak adlandırılmaktadır. Bununla birlikte üst üste bindirme kaynağı yapılan levhaların birleşme çizgileri de Şekil 6b'de görülmektedir.

Şekil 7a-d sırasıyla incelendiğinde $\mathrm{t}=1 \mathrm{sn}, \mathrm{h}=1.7 \mathrm{~mm}, \mathrm{v}=2000 \mathrm{dev} / \mathrm{dk}$ kaynak parametreleri kullanılarak yapılan birleştirmelerde, tamamlanmamış yeniden doldurma (boşluk) kusurları gözlemlenmiştir. Bu durum, yetersiz dönme hızı, dalma derinliği ve yetersiz sürtünme süresinden kaynaklandığı ve bu nedenle malzemenin plastize olamadan temas bölgelerinde boşluk ve bağlantısız bölgelere yol açtığı düşünülmektedir. Birleştirmelerde boşluk hatası, ciddi bir hacimsel kusurdur. Çentik etkisini tetikleyebilecek artık gerilim yoğunlaşmasına neden olabilir ve kötü korozyon direncine yol açabilir. Şekil $7 \mathrm{c}, \mathrm{d}$ 'de $\mathrm{t}=1.5 \mathrm{sn}, \mathrm{h}=2 \mathrm{~mm}, \mathrm{v}=2500$ da birleştirilen numunelerin bir önceki numunelere kıyasla daha başarılı ve boşluksuz bağlantılar oluşturduğu görülmüştür. Böylece ideal dönme hızı dalma derinliği ve kaynak süresi seçilerek bu kusurlar ortadan kaldırılabilir. Kaynak süresinin artması ile karıştırma bölgesinde ısı artışı meydana gelir. Bu artan ısı girdisi, daha iyi bir malzeme akışına yol açarak tamamlanmamış yeniden doldurma kusurunu ortadan kaldıracaktır [23]. 

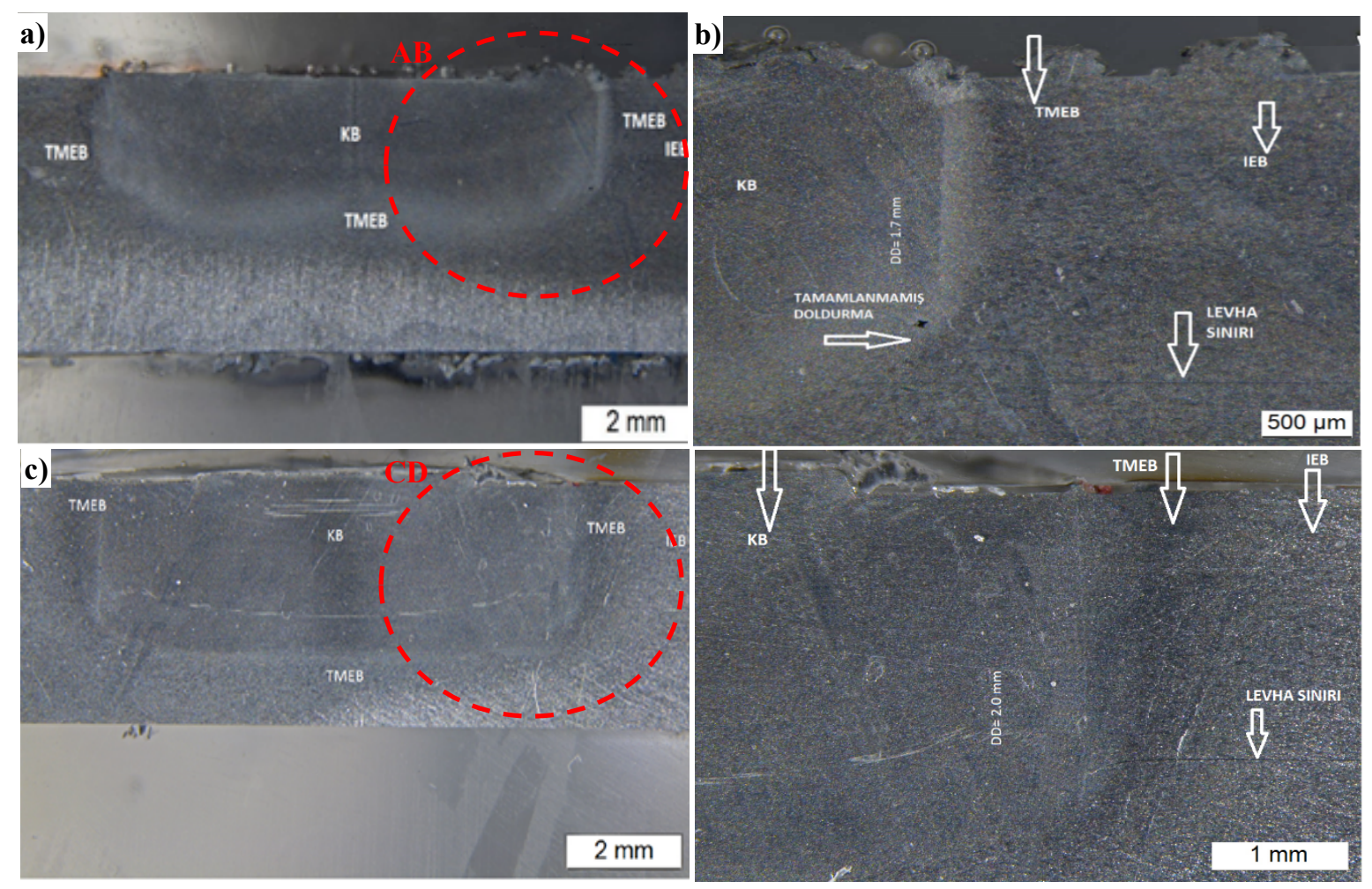

Şekil 7. a - d Farklı parametrelerde gerçekleştirilen TSKNK kaynak bölgelerinin metalografik kesitleri:

(a) A numunesi, $\mathrm{t}=1 \mathrm{sn}, \mathrm{h}=1.7 \mathrm{~mm}, \mathrm{v}=2000 \mathrm{dev} / \mathrm{dk}$, (b) $\mathrm{AB}$ kesitin büyültülmüş görüntüsü,

(c) J numunesi, $\mathrm{t}=1.5 \mathrm{sn}, \mathrm{h}=2 \mathrm{~mm}, \mathrm{v}=2500 \mathrm{dev} / \mathrm{dk},(\mathrm{d}) \mathrm{CD}$ kesitin büyültülmüş görüntüsü.

\subsection{Mekanik özellikler}

Tablo 3 ve Tablo 4'de 6061-T6 alüminyum alaşımına ait mekanik özellikler ve kaynaklı bağlantılara ait maksimum çekme mukavemeti değerleri sırasıyla verilmiştir. Şekil 8'de bu değerlere ait grafik verileri sırasıyla verilmiştir. Çekme testi sonuçları incelendiğinde, en yüksek çekme mukavemetinin $2.5 \mathrm{~mm}$ lik dalma derinliğine sahip numunelerde elde edildiği görülmektedir. Bu sonuca paralel olarak sırasıyla 2 ve $1.7 \mathrm{~mm}$ derinlik altında yapılan kaynakların çekme test verilerinde de kademeli ve tutarlı düşüşler gözlemlenmiştir. Bu durum, kaynak merkezinde yüksek 1sı girdisinin neden olduğu aşırı deforme olan tane yapısında pekleşmenin meydana gelmesi ve aynı şekilde isı tesiri etkisiyle daha viskoz ve akıcı plastize malzemenin, takımın temas ettiği her noktasını doldurmasıyla çekme testinde çentik etkisini azalttığı düşünülmektedir. Aynı zamanda kısa kaynak süresine sahip numunelerde elde edilen düşük mukavemet değerlerinin de mikroyapıda gözlemlenen doldurulmamış bölgelerin kaynak mukavemetini düşüren temel neden olduğu açıktır.

Tablo 3. 6061 T6 alüminyum alaşımının mekanik özellikler

\begin{tabular}{|c|c|c|c|}
\hline $\begin{array}{c}\text { Akma Mukavemeti (MPa) } \\
\text { min-max }\end{array}$ & $\begin{array}{c}\text { Çekme Mukavemeti (MPa) } \\
\text { min-max }\end{array}$ & Uzama (\%50) & Sertlik (brinel) \\
\hline $240-270$ & $260-310$ & 20 & 95 \\
\hline
\end{tabular}


Tekrar Doldurmalı Sürtünme Karıștırma Nokta Kaynaklı 6061-T6 Alüminyum Alaşımlı Bağlantıların Mikroyapı ve Mekanik Özelliklerinin İncelenmesi

Tablo 4. Deney parametrelerine bağlı çekme dayanımı değerleri

\begin{tabular}{|c|c|c|c|c|}
\hline Numune & $\begin{array}{c}\text { Kaynak Süresi } \\
\text { "t” (sn) }\end{array}$ & $\begin{array}{c}\text { Dalma Derinliği } \\
\text { "h“(mm) }\end{array}$ & $\begin{array}{c}\text { Takım Dönme Huzı } \\
\text { "v”(dev/dk) }\end{array}$ & $\begin{array}{c}\text { Maksimum } \\
\text { Çekme } \\
\text { Mukavemeti } \\
(\mathrm{MPa})\end{array}$ \\
\hline A & 1,0 & 1,7 & 2000 & 69,403 \\
\hline B & 1,0 & 1,7 & 2500 & 68,632 \\
\hline C & 1,0 & 2,0 & 2000 & 105,575 \\
\hline D & 1,0 & 2,0 & 2500 & 93,402 \\
\hline E & 1,0 & 2,5 & 2000 & 148,698 \\
\hline F & 1,0 & 2,5 & 2500 & 146,543 \\
\hline G & 1,5 & 1,7 & 2000 & 81,937 \\
\hline H & 1,5 & 1,7 & 2500 & 72,469 \\
\hline I & 1,5 & 2,0 & 2000 & 113,029 \\
\hline J & 1,5 & 2,0 & 2500 & 108,641 \\
\hline K & 1,5 & 2,5 & 2000 & 144,515 \\
\hline L & 1,5 & 2,5 & 2500 & 141,715 \\
\hline
\end{tabular}
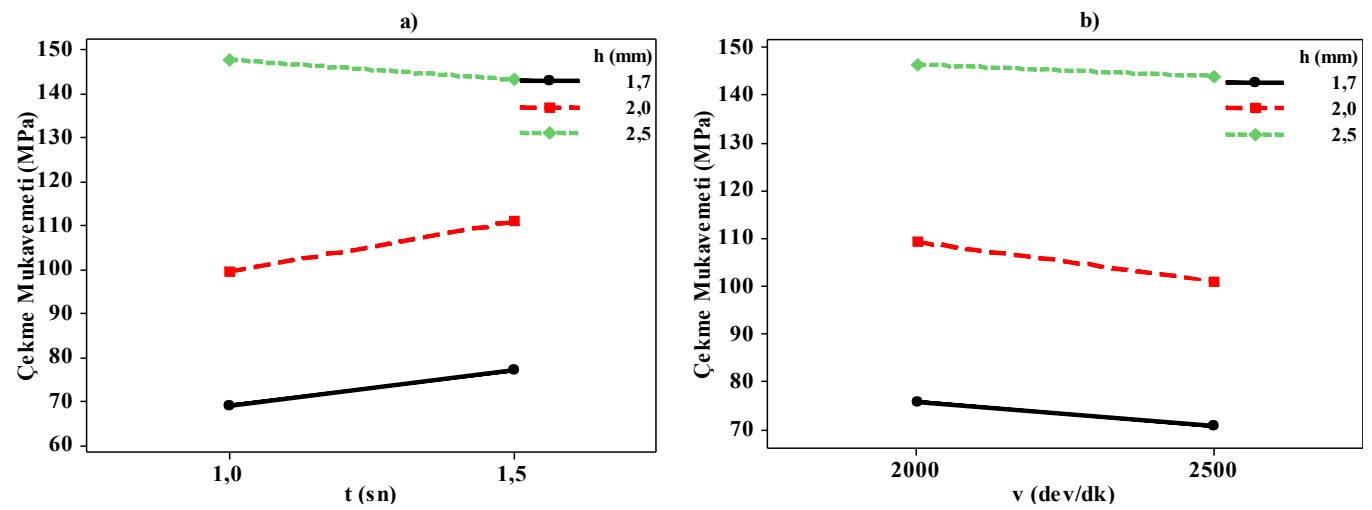

Şekil 8. Kaynak süresi (a) ve takım dönme hızının (b) çekme mukavemetine etkisi.

Şekil 8a’ da görüldüğü gibi takım dalma derinliği arttıkça kaynaklı birleştirmenin çekme mukavemeti artmıştır. Benzer şekilde kaynak süresinin artmasına bağlı olarak da çekme mukavemetinin arttığı görülmektedir. Ancak takım dalma derinliğinin $2,5 \mathrm{~mm}$ ve kaynak süresinin $1,5 \mathrm{sn}$ olduğu durumda kaynak bölgesinin birleşme mukavemeti nispeten düşük çıkmıştır. Şekil 8b, takım dönme hızı ve dalma derinliğinin kaynak mukavemeti arasındaki ilişkiyi göstermektedir. Görüldüğü üzere takım dalma derinliği arttıkça kaynak mukavemeti artmakta. Ancak, takım dönme hızı $2000 \mathrm{dev} /$ dak'dan 2500 dev/dak'ya çıktı̆̆ında kaynak mukavemetinin azaldığı görülmektedir. Kwee vd.[20], yapmış oldukları çalışmada takım dönme hızının artması ile kaynak mukavemetinin düştügünü belirtmişlerdir. Bu durum yüksek 1sı girdisine yol açan artan devir sayısının malzemenin içyapısında tane irileşmesine ve IEB nin genişlemesine neden olacağ sonucunu doğurmaktadır. Temelde mukavemeti düşüren nedenlerin başında bağlantısız bölgelerin varlığı olsa da literatür incelendiğinde aşırı 1sı girdisinin özellikle çökelme sertleşmeli Al alaşımlarında tane yapısını irileştirerek mekanik özellikleri kötüleştireceği bildirilmiştir $[24,25]$.

Şekil 9'da E ve B numunelerine ait Çekme Mukavemeti -\% Şekil değiştirme eğrileri ve deney sonrası numune fotoğrafları verilmiştir. Grafiklerden de görüldüğ̈̈ gibi, en yüksek çekme mukavemeti, $t=1 \mathrm{sn}, \mathrm{h}=2.5 \mathrm{~mm}, \mathrm{v}=$ $2000 \mathrm{dev} / \mathrm{dk}$ parametreleri ile birleştirilen E numunesinde 148,698 MPa olarak elde edilmiştir. En düşük kaynak mukavemeti ise $\mathrm{t}=1 \mathrm{sn}, \mathrm{h}=1.7 \mathrm{~mm}, \mathrm{v}=2500 \mathrm{dev} / \mathrm{dk}$ parametreleri ile birleştirilen $\mathrm{B}$ numunesinde $(68,632 \mathrm{MPa})$ elde edilmiştir. Bütün numuneler, sınırlı kaynak genişliğine sahip olması nedeniyle boyun vermeden kırılmışlardır. 

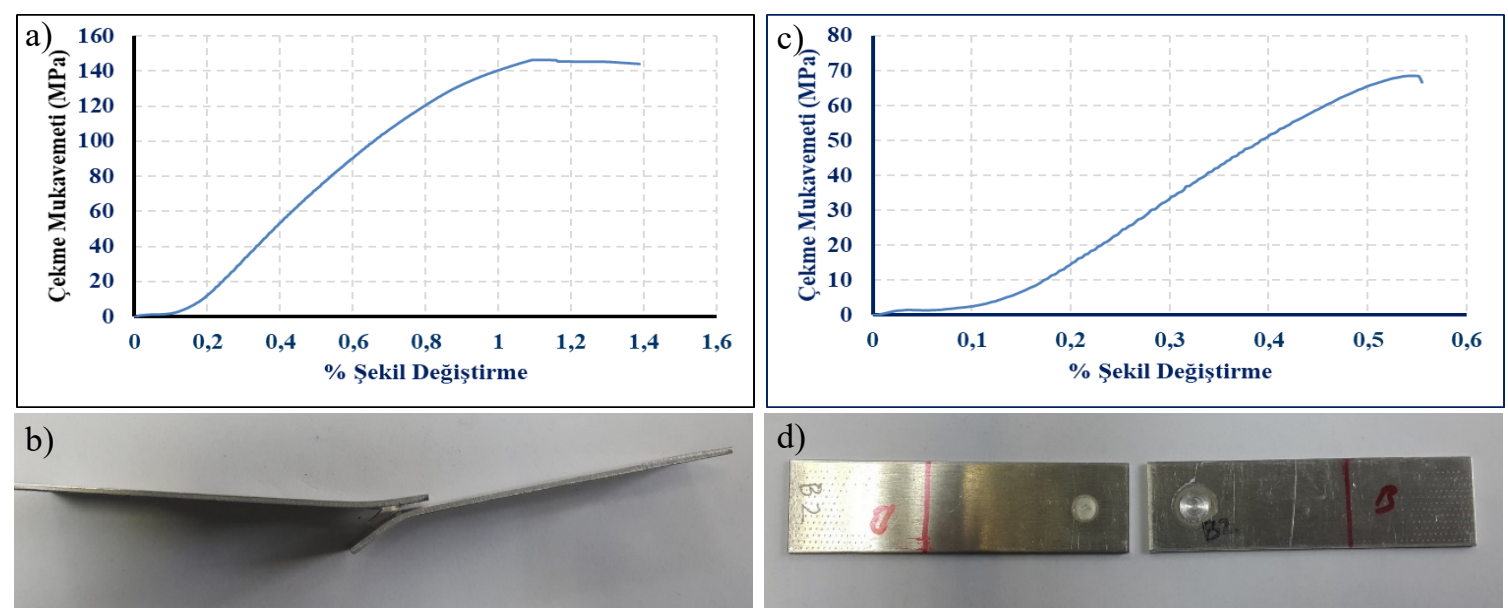

Şekil 9. Çekme test sonuçları (a) E numunesi için Çekme Mukavemeti -\% Şekil değiştirme grafiği (b) numune görüntüsü (c) B numunesi için Çekme Mukavemeti -\% Şekil değiştirme grafiği (d) numune görüntüsü

Tablo 5' de bütün numunelerin kaynak merkezinden ana malzemeye kadar olan bölge boyunca $2 \mathrm{~mm}$ aralıklarda alınan mikro sertlik ölçüm sonuçları ve bu değerlere ait mikrosertlik grafik Şekil 10'da sırasıyla verilmiştir.

Tablo 5. Numuneler için belirlenen noktalardan alınan mikrosertlik değerleri (HV)

\begin{tabular}{|c|c|c|c|c|c|c|}
\hline Numune & $\mathbf{1}$ & $\mathbf{2}$ & $\mathbf{3}$ & $\mathbf{4}$ & $\mathbf{5}$ & $\mathbf{6}$ \\
\hline $\mathbf{A}$ & 95 & 93 & 86 & 81 & 93 & 105 \\
\hline $\mathbf{B}$ & 94 & 93 & 85 & 80 & 92 & 103 \\
\hline $\mathbf{C}$ & 94 & 91 & 77 & 74 & 89 & 98 \\
\hline $\mathbf{D}$ & 95 & 92 & 75 & 73 & 88 & 99 \\
\hline $\mathbf{E}$ & 93 & 92 & 71 & 70 & 83 & 91 \\
\hline F & 92 & 90 & 70 & 67 & 81 & 90 \\
\hline $\mathbf{G}$ & 94 & 92 & 84 & 79 & 91 & 104 \\
\hline $\mathbf{H}$ & 93 & 92 & 82 & 78 & 90 & 103 \\
\hline $\mathbf{I}$ & 92 & 90 & 74 & 71 & 88 & 97 \\
\hline $\mathbf{J}$ & 93 & 91 & 73 & 70 & 86 & 98 \\
\hline K & 91 & 89 & 65 & 63 & 83 & 89 \\
\hline $\mathbf{L}$ & 90 & 88 & 64 & 62 & 81 & 87 \\
\hline
\end{tabular}

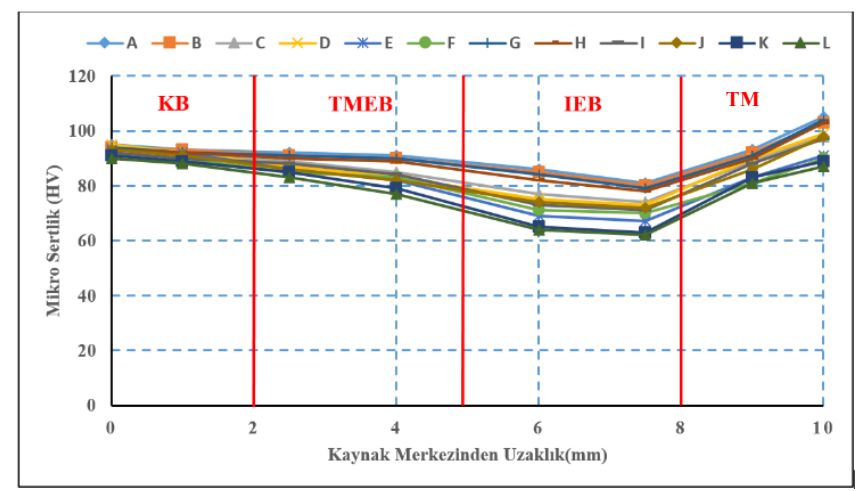

Şekil 10. Numunelere ait mikrosertlik dağılımı

Tablo 5 ve Şekil 10'daki veriler incelendiğinde, farklı parametrelerde yapılan kaynak numunelerinden ölçülen sertlik değerleri benzer dağı̆lımlar gösterdiği görülmektedir. Kaynak bölgesinin mikro sertliğinin temel 
malzemeden nispeten daha düșük olduğu saptanmıștır. TMEB / IEB ara yüzünde minimum sertlik değerinin düştüğü, TMEB / KB geçiş bölgesinde ise sertliğin tekrar yükseldiği tespit edilmiştir. Bilindiği üzere 6061-T6 alüminyum alaşımları çökeltme sertleştirmesi ile mekanik özellikleri iyileştirilmiş alaşımlardır. Bu nedenle yüksek 1Sı girdisi çökelme sertleşmeli alaşımlarda sınırlı oranda mukavemet kaybına yol açmaktadır. Kaynak esnasında 1Sı girdisini artıracak parametrelerde yapılan kaynaklar, kaynak bölgesinde farklı tane boyutlarına sahip bölgelerin oluşmasına sebep olmuştur. Bu durum bölgesel olarak mikrosertlik farklılıklarını ortaya çıkarmaktadır.

TMEB/KB nin şiddetli yoğun plastik deformasyona uğraması bu bölgelerde dövülen tanelerin incelerek plastik deformasyon sertliğini ve pekleşme meydana getirmesi, IEB'den daha yüksektir, Bu durum KB bölgesinde IEB ye nazaran daha yüksek mikrosertlik değerleriyle sonuçlanır. Sadece 1sı baskısı altında kalan IEB deki mekanik zayıflığın nedeni ise literatürde de desteklenen [26] çökeltinin çözülerek bölgenin çökelme sertleştirme kabiliyetini yitirmesine bağlanabilir. Ayrıca TM'nin en yüksek sertlik değerleri sergilemesindeki asıl nedenin, ısının bu bölgeyi kısmi etkilemesi olarak açıklanabilir.

\subsection{Varyans analizi (ANOVA)}

Parametre seviyelerinin optimum kombinasyonlarını doğru bir şekilde değerlendirmek için kaynak parametrelerinin kaynak performansı üzerindeki etkisinin anlaşılması gerekir. Bu, Varyans analizi yapılarak elde edilebilir. $\% 95$ güven düzeyinde ( $\alpha=\% 5$ hata seviyesinde) yapılan ANOVA testi sonucunda elde edilen veriler Tablo 6'da verilmiştir. Burada, her bir parametrenin kaynak mukavemeti üzerindeki anlamlılık düzeyini gösteren P değerleri ile serbestlik derecesi, kareler toplamı, kareler ortalaması, F değerleri ve yüzde etki oranları görülmektedir. ANOVA tablosunda, $\mathrm{P}<0,05$ ise parametrelerin kaynak mukavemeti üzerinde anlamlı bir etkisi olduğu kabul edilir [27]. Varyans analiz sonuçlarına göre kaynak mukavemeti üzerinde en etkin parametre \% 96,76 katkı oranı ile dalma derinliği olmuştur.

Tablo 6. Kaynak mukavemeti için varyans analiz sonuçları

\begin{tabular}{|c|c|c|c|c|c|c|}
\hline $\begin{array}{c}\text { Deney } \\
\text { Parametreleri }\end{array}$ & $\begin{array}{c}\text { Serbestlik } \\
\text { Dereceleri }\end{array}$ & $\begin{array}{c}\text { Kareler } \\
\text { Toplami }\end{array}$ & $\begin{array}{c}\text { Kareler } \\
\text { Ortalaması }\end{array}$ & F-Değeri & P-Değeri & $\begin{array}{c}\text { Etki } \\
\text { Oran1 \% }\end{array}$ \\
\hline $\mathrm{t}(\mathrm{sn})$ & 1 & 304327 & 304327 & 2,75 & 0,141 & 0,69 \\
\hline $\mathrm{h}(\mathrm{mm})$ & 2 & 42398089 & 21199044 & 191,32 & 0,000 & 96,76 \\
\hline $\mathrm{v}(\mathrm{dev} / \mathrm{dk})$ & 1 & 339697 & 339697 & 3,07 & 0,123 & 0,78 \\
\hline Hata & 7 & 775629 & 110804 & & & 1,77 \\
\hline Toplam & 11 & 43817741 & & & & \\
\hline
\end{tabular}

Ayrıca, parametrelerin kaynak mukavemeti üzerindeki etki grafikleri Şekil 11'de verilmiştir. Grafiklerde, Kesikli çizgi kaynak mukavemetinin belirlenmesinde uygulanan kuvvetin toplam ortalama değerini göstermektedir. Kaynak süresi (t) ve takım dönme hızının (v) kuvvet üzerindeki küçük katkısı, nispeten daha düşük eğimli bir eğri ile temsil edilirken. Takım dalma derinliğinin kaynak mukavemeti üzerindeki etkisi (\% 96,76) varyasyon analizi ile bir kez daha doğrulanmıştır.

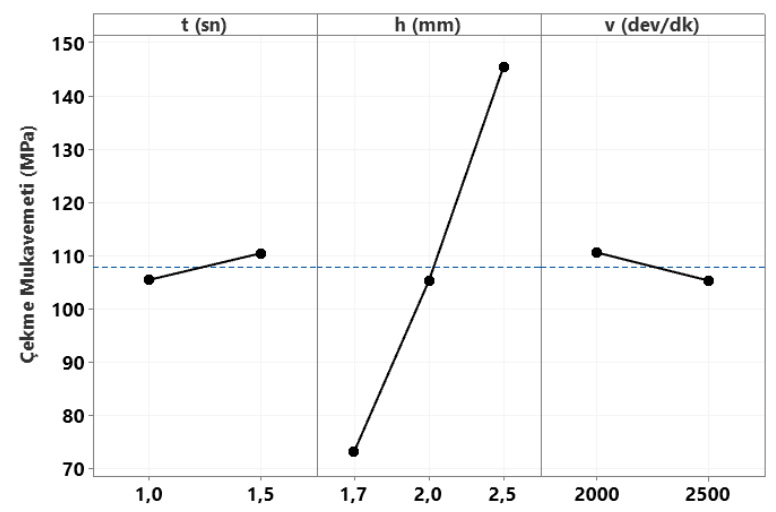

Şekil 10. Kaynak parametrelerinin kuvvet üzerindeki etkileri 


\section{Sonuçlar}

AA6061-T6 alaşımı tekrar doldurmalı sürtünme karıştırma nokta kaynağı (TSKNK) yöntemi ile başarılı bir şekilde birleştirilerek aşağıda sıralanan sonuçlar elde edilmiştir.

1. Kaynaklı bağlantıların ara yüzey mikroyapısal özellikleri incelendiğinde dört farklı bölgenin varlı̆̆ belirlenmiştir. Bunlar sırasıyla, kaynak merkezindeki takım bileziğinin levhayı karıştırdığı karıştırma bölgesi (KB), termo-mekanik etkilenen bölge (TMEB), 1S1 etkili bölge (IEB) ve son olarak temel malzemedir (TM).

2. Kaynak bölgelerinde mikrosertlik değişimleri incelendiğinde en yüksek değerler TM ve KB'de tespit edilirken TMEB ve IEB'de kademeli düşüşler görülmüş. Bu sonuca göre, IEB deki düşüşlerin temel nedeni; kaynak bölgesinde meydana gelen 1sı artışının sebep olduğu iri taneli yapı nispeten daha düşük mikrosertlik değerlerinin ortaya çıkmasına neden olmuştur.

3. Yapılan çekme testi sonucunda işlem parametrelerinin (takım dönme hızı, kaynak süresi ve dalma derinliği) kaynak bölgesi mukavemetine etkisi incelenmiştir. Bunun sonucunda en yüksek dayanım $\mathbf{t}=$ $1 \mathrm{sn}, \mathrm{h}=2.5 \mathrm{~mm}, \mathrm{v}=2000 \mathrm{dev} / \mathrm{dk}$ parametreleri altında birleştirilen E numunesinde 148,698 MPa olarak kaydedilmiștir.

4. Kaynak parametrelerinin kaynak bölgesinin mukavemeti üzerindeki etkisi karşılaştırıldığında, bütün numunelerde dalma derinliğinin $2.5 \mathrm{~mm}$ seçildiği gruplarda en yüksek çekme verileri elde edilmiştir.

5. Kaynak parametrelerinin kaynak bölgesinin mukavemeti üzerindeki etkisinin belirlenmesi amacı ile yapılan ANOVA test sonuçlarına göre en etkin parametre \% 96,76 katkı oranı ile dalma derinliği (h) olduğu sonucuna varılmıştır.

\section{Teşekkür}

Bu çalışma, Kürşat DEMİR tarafından tamamlanan, Fırat Üniversitesi Fen Bilimleri Enstitüsü Mekatronik Mühendisliği Programı’nda “6061 T6 Alüminyum Alaşımlarının Sürtünme Karıştırma Nokta Kaynağı Yöntemi İle Birleştirilmesi, Mekanik ve Mikroyapısal Özelliklerinin İncelenmesi ” adı ile kayıtlı yüksek lisans tezindeki verilerden üretilmiştir.

\section{Kaynaklar}

[1] Huda Z, Taib NI, Zaharinie T. Characterization of 2024-T3 an aerospace aluminum alloy. Materials Chemistry and Physics 2009;113(2-3): 515-517.

[2] Miller WS, Zhuang L, Bottema J, Wittebrood AJ, De Smet P, Haszler A, Vieregge A. Recent development in aluminum alloys for the automotive industry. Materials Science and Engineering 2000; A, 280: 37-49.

[3] Dursun T, Soutis C. Recent developments in advanced aircraft aluminum alloys. Materials and Design 2014; 56: 862-871.

[4] Mert Ş, Mert S. Sürtünme karıştırma nokta kaynak yönteminin incelenmesi. İleri Teknoloji Bilimleri Dergisi 2013; 2(1): 26-35.

[5] Suryanarayanan R, Sridhar VG. Experimental investigation on the influence of process parameters in Friction stir spot welded dissimilar aluminum alloys. Materials Today: Proceedings 2020; 27: 529-533.

[6] Shen Z, Yang X, Zhang Z, Cui L, Li T. Microstructure and failure mechanisms of refill friction stir spot welded 7075-T6 aluminum alloy joints. Materials and design 2013; 44: 476-486.

[7] Li WY, Chu Q, Yang XW, Shen JJ, Vairis A, Wang WB. Microstructure and morphology evolution of probe less friction stir spot welded joints of aluminum alloy. Journal of Materials Processing Technology 2018; 252: 69-80.

[8] Kahraman B. Otomotiv endüstrisinde kullanılan 5754 alüminyum alaşımı sacların direnç nokta kaynağı (RSW) ve sürtünme karıştırma nokta kaynağı (FSSW) yöntemleri ile birleştirilmesi. Yüksek Lisans tezi, Kocaeli Üniversitesi, Fen Bilimleri Enstitüsü, 2009.

[9] Hong SH, Sripichai K, Yu CS, Avery K, Pan J, Pan TY, Santella M. Failure modes of friction stir spot welds in lap-shear specimens of dissimilar advanced high strength steels under quasi-static and cyclic loading conditions. SAE International Journal of Materials and Manufacturing 2012; 5(2): 375-381.

[10] Ji S, Li Z, Wang Y, Ma L, Zhang L. Material flow behavior of refill friction stir spot welded LY12 aluminum alloy. High Temperature Materials and Processes 2017; 36(5): 495-504.

[11] Buffa G, Fratini L, Piacentini M. On the influence of tool path in friction stir spot welding of aluminum alloys. Journal of Materials Processing Technology 2008; 208: 309-317.

[12] Li Z, Ji S, Ma Y, Chai P, Yue Y, Gao S. Fracture mechanism of refill friction stir spot-welded 2024-T4 aluminum alloy. The International Journal of Advanced Manufacturing Technology 2016; 86(5): 1925-1932.

[13] Xu Z, Li Z, Ji S, Zhang L. Refill friction stir spot welding of 5083-O aluminum alloy. Journal of Materials Science and Technology 2018; 34(5): 878-885. 
[14] Tier MD, Rosendo TS, Santos JF, Huber N, Mazzaferro JA, Mazzaferro CP, Strohaecker TR. The influence of refill FSSW parameters on the microstructure and shear strength of 5042 aluminum welds. Journal of Materials Processing Technology 2013; 213(6):, 997-1005.

[15] Nasiri AM, Shen Z, Hou JSC, Gerlich AP. Failure analysis of tool used in refill friction stir spot welding of Al 2099 alloy. Engineering Failure Analysis 2018; 84: 25-33.

[16] Kubit A, Wydrzynski D, Trzepiecinski T. Refill friction stir spot welding of 7075-T6 aluminum alloy single-lap joints with polymer sealant interlayer. Composite Structures 2018; 201: 389-397.

[17] Yang XW, Fu T, Li WY. Friction Stir Spot Welding: A review on joint macro and micro structure, property, and process modelling. Advances in Materials Science and Engineering. 2014; 1-11.

[18] Shena Z, Ding Y, Gopkalo O, Diak B, Gerlich AP. Effects of tool design on the microstructure and mechanical properties of refill friction stir spot welding of dissimilar Al alloys, Journal of Materials Processing Tech 2018; 252: 751-759.

[19] Shi Y, Yue Y, Zhang L, Ji S, Wang Y. Refill Friction Stir Spot Welding of 2198-T8 Aluminum Alloy. Trans Indian Inst Met 2018; 71(1): 139-145.

[20] Kwee I, Waele WD, Faes K. Weldability of high-strength aluminum alloy EN AW-7475-T761 sheets for aerospace applications, using refill friction stir spot welding. Welding in the World. 2019; 63: 1001-1011.

[21] Mishra RS, Ma ZY. Friction stir welding and processing. Materials Science and Engineering 2005; 50:1-78.

[22] Santos TG, Miranda RM, Vilaca P, Teixeira JP, Santos J. Microstructural mapping of friction stir welded AA 7075-T6 and AlMgSc alloys using electrical conductivity. Science and Technology of Welding and Joining 2011;16: 630-5.

[23] Kwee I, Faes K. Refill friction stir spot welding of EN AW- 7075 T6 to EN AW-7075 T6 sheets. Part 1: effect of the welding parameters on the microstructure, surface temperature and hardness of refill friction stir spot welds of EN AW075-T6. Welding and Cutting 2018; 17(5): 384-390.

[24] Jata K, Semiatin SL. Continuous dynamic recrystallization during friction stir welding of high strength aluminum alloys. Scripta Mater 2000; 43: 743-749.

[25] Sato YS, Kokawa H, Ikeda K, Enomoto M, Jogan S, Hashimoto T. Precipitation sequence in friction stir weld of 6063 aluminum during aging. Metall. and Mater. Trans. A 2001; 32: 3125-3130.

[26] Okamura H, Aota K, Ezumi M. Friction stir welding of aluminum alloy and application to structure. J. Japan Ins. L. Metals. 2000; 50: 166-172.

[27] Günay M, Yücel E. Application of Taguchi method for determining optimum surface roughness in turning of high-alloy white cast iron. Measurement. 2013; 46 (2): 913-919. 